\title{
Multi-Agent System for Detecting Elderly People Falls through Mobile Devices
}

\author{
Patricia Martín, Miguel Sánchez, Laura Álvarez, \\ Vidal Alonso, and Javier Bajo
}

\begin{abstract}
Falls in the elderly and disabled people represent a major health problem in terms of primary care costs facing the public and private systems. This paper presents a multi-agent system capable of detecting falls through sensors in a mobile device and act accordingly at runtime. The new system incorporates a fall detection algorithm based on machine learning and data classification using decision trees. The base of the system are three types of interrelated agents that coordinate to know the position of a user from data obtained through a mobile terminal, and GPS position, which in case of fall may be sent via SMS or by an automatic call. The proposed system is self-adaptive, since as new fall date is incorporated, the decision mechanisms are automatically updated and personalized taking into account the user profile.
\end{abstract}

Keywords: Context-Aware, Multi-Agent Systems, Decision trees.

\section{Introduction}

Falls are one of the most serious problems in the geriatric care because they are one of the fundamental causes of injury and even death in elderly people. According to the World Health Organization (WHO), between $28 \%$ and $34 \%$ of people 65 and older experience at least one fall per year [1]. In Spain the data are also alarming. The on mortality of the Institute of Health Carlos III in 2007 reveal that the greater the age the higher the mortality rate for accidental falls, exceeding even the percentage of some types of cancer. Moreover, various authors [1, 2, 3, 4, 5, $6,7]$, consider that falls are due to a combination of multiple factors, and can be

Patricia Martín · Miguel Sánchez · Laura Álvarez · Vidal Alonso · Javier Bajo Universidad Pontificia de Salamanca, c/ Compañía 5,

37002 Salamanca, Spain

e-mail: patrimrodilla@usal.es, miguel@chocosoft.net,

lalvarezba@gmail.com, \{valonsose, jbajope\} @upsa.es

P. Novais et al. (Eds.): Ambient Intelligence - Software and Applications, AISC 92, pp. 93-99. springerlink.com

(C) Springer-Verlag Berlin Heidelberg 2011 
grouped into two main groups: intrinsic and extrinsic factors, and consequences of they are not only physical but also psychological, social and economic [2, 8, 9].

This situation makes necessary to investigate in new solutions aimed at fall's detection in an effective an non-intrusive manner. This paper proposes an innovative multi-agent system specifically designed to detect falls and act accordingly. The core of the system is a detection mechanism built into a mobile phone. This mechanism allows a simple and non-intrusive detection of falls, and enables ubiquitous communication mechanisms.

The reminder of the paper is structured as follows: First we review the state of the art of the technologies involved in the work. In section 3 the proposed multiagent system is presented. Finally, Section 5 presents the results and conclusions obtained after applying the architecture to a real case study.

\section{Related Work}

After consulting the literature, there not exists a multi-agent system aimed at the detection of falls of elderly people making use of mobile devices for detecting the fall. Different researchers have tackled the problem from different perspectives, and there are three elements that give an innovative character to this project: i) the focus on the mobile device, which provides a certain level of independence to the physical detection component, ii) the multi agent system, that provides ubiquitous distributed solving abilities and learning capacity, and iii) the fact that the system is able to perform additional functionalities within the field of e-Health and care of the elderly.

A study of the related work reveals that there exist projects aimed at designing multi-agent system for the detection of falls at home [11], with agents located in a central computer connected to a health center and various sensors placed around the house, and a device specially built for this purpose. The above solution is focused in the field of home automation, and as other specific approaches [18] [20] does not provide additional functionality (the mobile phone itself) to the patient. On the other hand, there are specific projects aimed at finding an effective algorithm for the detection of falls using three-axis accelerometer [13] [16], gyroscopes [17] [13], or a combination of both [12]. These systems have evolved during the last years, because they were initially conceived to detect falls or collisions. The current systems try to detect the problems in advance (pre-impact detection) [15] [12]. Some of the existing approaches use the threshold as the key component of the detection algorithm. The threshold is the sharp difference of gravity between two axis of the accelerometer. The approach proposed in this paper makes use of the threshold, but it is not a fundamental component. It is necessary to note that these solutions do not use agents for decision making, and there is not standardized solution. Some authors focus on semi-supervised learning techniques to increase the accuracy of fall detection, making use of video images for posture recognition [21], and even sounds [19] [22] or extraction of 3D trajectories of the body or body parts [23].

The system presented in this paper makes use of intelligent agent to improve its learning abilities. The agents make use of the measurements of two routine 
medical test (get up and go, get \& go), as well as of the patient data. The main novelties of the approach presented in this paper are the distributed problem solving abilities of the multi-agent system, the use of a mobile phone as a fall detector, that can accurately detect whether there is a fall and alert and the medical center or caregiver more close, without limiting the rest of the functionalities of the phone. In addition, the system covers other needs of elderly users, as reminders of appointments or taking medication.

\section{Proposed Architecture}

The proposed approach primarily based on harnessing the benefits of multi-agent systems in the problem of fall detection. A multi-agent system can notably help to make automatic decisions and to integrate advanced detection mechanisms into mobile phone devices. Intelligent agents are very appropriated to be installed into mobile devices, and given the increasing relevance that this kind of devices are acquiring in our society, sensing and making decisions from mobile devices can notably help to develop ubiquitous, un-obstructive and intelligent environments. With the current inter-connection possibilities, the decision may be taken from the device itself or remotely, based on a more complex analysis of the information. The approach makes use of the phone's functionalities to manage an automatic alert system, connected to a care center that takes advantage of the GPS system to provide accurate information about the patient location. The architecture of the proposed multi-agent system is composed of three agent types that collaborate to detect falls: Sensor agent, Classifier agent and Actuator agent. The structure of the multi-agent architecture can be observed in Figure 1. The agent types are explained in detail in the following sub-sections.

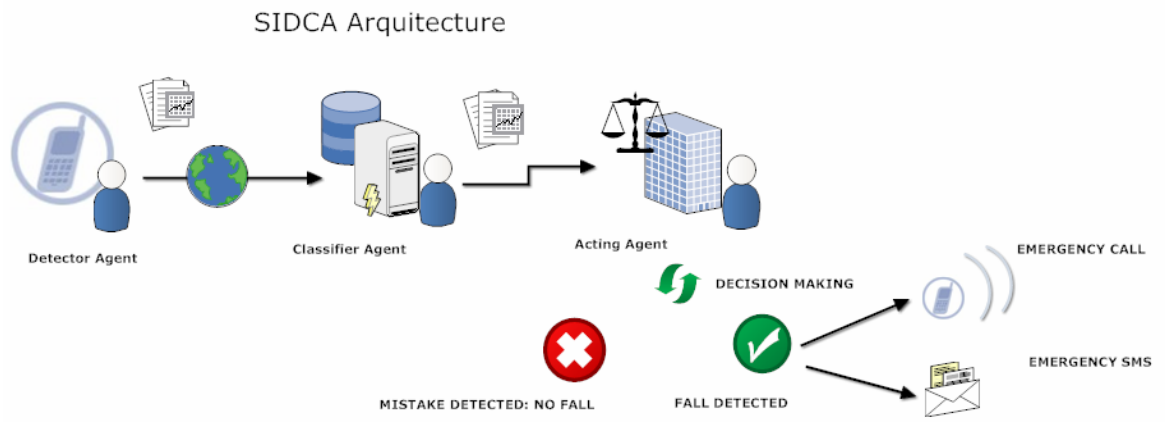

Fig. 1 Multi-agent architecture to manage fall detection

\subsection{Sensor Agent}

It is an agent specially designed to be installed on mobile devices. It acts as an interface between the user and the rest of the system and has advanced capabilities 
for fall detection. The Sensor agent uses the accelerometers of a mobile phone to collect data of the movements of the elderly person carrying the phone. In this way, the agent gets the raw data that is used to obtain a classification and identify falls. This lightweight classification process is based on the use of previous experiences: the system evaluates similarity to previously stored patterns. If the result of the classification is not accurate, then the agent communicates with the Classifier agent to carry out an advanced classification.

It is necessary to take into account that the mobile device must be equipped with three-axis accelerometer $(\mathrm{X}, \mathrm{Y}, \mathrm{Z})$ on a single silicon chip, including in that the electronics that processes the signals. These kinds of accelerometers are currently available in most of the terminals on the market. Thanks to this technology, the Sensor agent located in the mobile can manage the three main values required for the classification process: rotation, translation and space and temporal situation of the mobile device. An initial position is taken as a reference. The agent identifies eight different patterns: standing, walking, climbing or descending stairs, sitting or to detect fall forward and fall back. It is also necessary to take in mind that the system uses the JADE Leap suite for Android. This technology allows us to integrate the Sensor agent into the multi-agent system.

\subsection{Classifier Agent}

The classifier agent is located in the care center and manages the data recorded by the Sensor agent. The Classifier agent implements a decision algorithm based on the J48 decision tree. The agent learns progressively and dynamically recalculates the values that are given to the position of the falls for that particular user. This agent is necessary, since it is in charge of personalizing the fall patterns to the user profile. The profile takes into account the motion of each elder or dependent person, and the concrete peculiarities. Basically the decision-making mechanism is based on $\mathrm{J} 48$ decision trees, an adaptation of the $\mathrm{C} 4.5$ algorithm, which is common for classification. Basically, the agent:

- Works with continuous values for attributes, separating the possible results in 2 branches $\mathrm{Ai}<=\mathrm{N}$ y $\mathrm{Ai}>\mathrm{N}$.

- The trees are less dense, and each sheet covers a distribution of classes and not a particular class.

- It uses the "divide and conquer" method to generate the initial decision tree from a training data set, and continues recursively. Each of the iterations is carried out when the Classifier agent receives new data from the Sensor agent.

- Implements a strategy based on the use of the gain ratio criteria, defined as I $(\mathrm{Xi}, \mathrm{C}) / \mathrm{H}(\mathrm{Xi})$. Thus it is possible to avoid potential benefits to the selection of those variables with the greatest number of possible values.

Once the Sensor agent has classified the new input data, it sends the border values calculated for the decision tree, together with the input data, to the Actuator agent. 


\subsection{Actuator Agent}

The actuator agent is located in the care center and stores all the information captured by the Sensor agent and processed by the Classifier agent. With this information, the agent knows if the user has suffered a fall or not, and whether there has been an anomaly in the pattern of falling for the user. The actuator agent decides the action required for the emergency. The agent is also in charge of registering false positives and informs the Sensor and Classifier agents about these situations. When the Actuator agent receives information about a fall detection, it executes two actions:

- The mobile terminal performs an automatic emergency call to the emergency number. It also detects the closest medical center or the emergency number more appropriate depending on the user profile.

- The mobile terminal automatically sends an SMS to the contact person configured by the user. This SMS contains the GPS position of the mobile terminal, and information about the potential fall details.

\section{Results and Conclusions}

The system was tested under simulation conditions. The test's parameters were set up using previous postural studies related to elderly people. Over three months of testing 500 files were obtained using data from real falls. The Sensor agent received the input data and processed it into XML (eXtensible Markup Language), keeping this format for the rest of the agents. An example of XML file is shown in Figure 2. As can be seen in Figure 2, stores the data obtained by the accelerometer: time, $\mathrm{x}, \mathrm{y}$ and $\mathrm{z}$ values, pitch and roll.

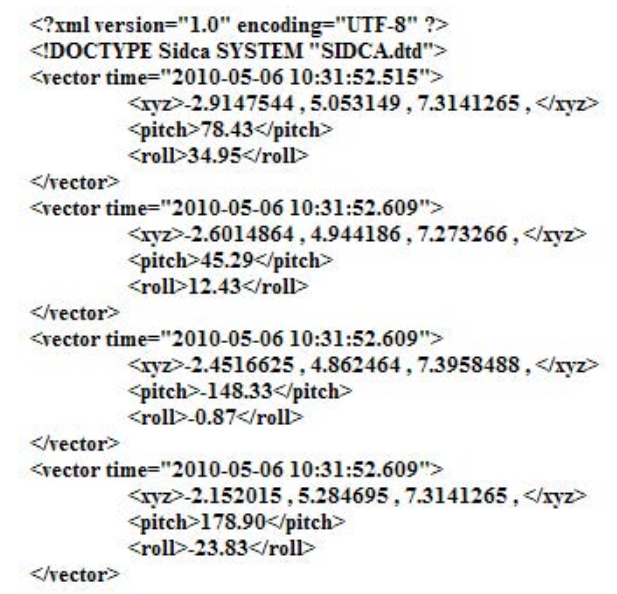

Fig. 2 Example of XML file used by the agents in the system 
During three months the system was trained and tuned trying to obtain a good learning rate. The system can successfully distinguish different positions (and five types of falls): standing, walking, climbing or descending stairs, sitting or to detect fall forward and fall back. The system is able to recalculate the parameters of the user in real-time. The error rate decreases as the system learns from the new input data, and the minimum mean quadratic error obtained in the experiments was 0,16 .

The main advantages of the proposed approach can be summarized as follows:

- The computational cost is minimal. The algorithm for the mobile terminal is very light and causes a low battery consumption.

- The reliability of data processing in the three agents is acceptable.

- The traffic generated into the network is acceptable and very appropriated for distributed systems of this kind.

- The system provides a mechanism to reduce the impact of the falls for elderly people, providing and automatic and quick response to the potential incidents.

- The system provides financial benefits. The economic consequences of falls in elderly people is very costly to health services [2] because they must meet various demands such as: the initial hospitalization after a fall with serious consequences, treatments and surgical and orthopedic the need for a further period of rehabilitation to try to restore the patient to their prior functional status, and extra care of elderly hospital with minor injuries and both caregivers and institutionalization costs.

The results obtained in the experiments are promising, but need to be improved using a more extensive dataset and evaluating the approach in real scenarios. Our future work focuses on obtaining more specialized algorithms for classification and learning.

Acknowledgements. This study has been supported by the Spanish Ministry of Science and Innovation project TRA2009_0096.

\section{References}

1. Suelves, J.M., Martínez, V., Medina, A.: Lesiones por caídas y factores asociados en personas mayores de Cataluña, España. Rev. Panam Salud. Publica. 27(1), 37-42 (2010)

2. Carro García, T., Alfaro Hacha, A.: Caídas en el anciano. Residentes de Geriatria Hospital Virgen de Valle. Toledo

3. Quiénes son ancianos frágiles - ancianos de riesgo? Estudio en personas mayores de 65 años del Área Sanitaria de Guadalajara

4. Esmeralda, M.R., et al.: Incidencia de caídas en la Unidad de Hemodiálisis del Hospital General de Vic (Barcelona). Rev. Soc. Esp. Enferm. Nefrol. 11(1), 6469 (2008)

5. Prat, I., Fernandez, E., Martinez, S.: Detección del riesgo de caídas en ancianos en atención primaria mediante un protocolo de cribado. In: 2007 Área Básica de Salud de Palamós. Serveis de Salut Integrats Baix Empordà. Palamós. Girona. España (2007) 
6. Papiol, M., Duaso, E., RodríguezCarballeira, M., Tomás, S.: Identificación desde un servicio de urgencias de la población anciana con riesgo de caída que motiva ingreso hospitalario. In: Servicio de Urgencias y Unidad Funcional de Geriatría. Hospital Mutua de Terrassa, Barcelona (2003)

7. Sociedad española de enfermería de urgencias y Emergencias. Prevención de caídas. Recomendación científica 10/05/10 de 25 de junio de (2009)

8. da Gama Silva, Z.A., Gomez, A., Sobral, M.: Epidemiología de caídas de ancianos en España: Una revisión sistemática. Rev. Esp. Salud Publica. 82(1), 4355 (2007)

9. Lázaro, A.: Características de las caídas de causa neurológica en ancianos

10. Lázarodel Nogal, M., LatorreGonzález, G., GonzálezRamírez, A., RiberaCasado, J.M.:

11. Pan, J.I., Yung, C.J., Liang, C.C., Lai, L.F.: An Intelligent Homecare Emergency Service System for Elder Falling. In: Proceedings of IFMBE World Congress on Medical Physics and Biomedical Engineering, vol. 14 (2006)

12. Nyan, M.N., Tay, F.E.H., Murugasu, E.: A wearable system for preimpact fall detection. Journal of Biomechanics 41, 3475-3481 (2008)

13. Bourke, A.K., Lyons, G.M.: A thresholdbased falldetection algorithm using a biaxial gyroscope sensor. Medical Engineering \& Physics 30(1), 8490 (2008)

14. Bourke, A.K., O’Brien, J.V., Lyons, G.M.: Evaluation of a thresholdbased triaxial accelerometer fall detection algorithm. Gait \& Posture 26(2), 194-199 (2007)

15. Bourke, A.K., O’Donovan, K.J., ÓLaighin, G.: The identification of vertical velocity profiles using an inertial sensor to investigate preimpact detection of falls. Medical Engineering \& Physics 30(7), 937-946 (2008)

16. Kumar, A., Rahman, F., Lee, T.: IFMBE. In: Proceedings: 13th International Conference on Biomedical Engineering ICBME 2008, Singapore, December 3-6 (2009)

17. Lindemann, U., Hock, A., Stuber, M., Keck, W., Becker, C.: Evaluation of a fall detector based on accelerometers: A pilot study. Medical and Biological Engineering and Computing 43(5) (October 2005)

18. Lustrek, M., Kaluza, B. (2009) Fall detection and activity recognition with machine learning. Slovenian Society Informatika, report of (May 2009)

19. Zhang, T., Wang, J., Xu, L., Liu, P.: Fall Detection by Wearable Sensor and OneClass SVM Algorithm. Intelligent Computing in Signal Processing and Pattern Recognition 345 (2006)

20. Doukas, C., Maglogiannis, I.: Advanced patient or elder fall detection based on movement and sound data. Pervasive Computing Technologies for Healthcare (2008)

21. Sixsmith, A., Johnson, N.: A Smart Sensor to Detect the Falls of the Elderly, vol. 3(2), pp. 42-47. IEEE Computer Society, Los Alamitos (2004)

22. Londei, S.T., Rousseau, J., et al.: An intelligent videomonitoring system for fall detection at home: perceptions of elderly people. Journal of Telemedicine and Telecare 15(8), 383-390 (2009)

23. Zigel, Y., Litvak, D., Gannot, I.: A Method for Automatic Fall Detection of Elderly People Using Floor Vibrations and Sound-Proof of Concept on Human Mimicking Doll Falls. IEEE Transactions on Biomedical Engineering 56(12), 2858-2867 (2009)

24. Rougier, C., Meunier, J.: Demo: Fall Detection Using 3D Head Trajectory Extracted From a Single Camera Video Sequence. Journal of Telemedicine and Telecare 11(4) (2005) 
